\title{
Welcome Letter
}

Dear Colleagues and Participants,

It is a great pleasure to welcome colleagues and participants from around the world to the $1^{\text {st }}$ International Conference on Tropical Wetland Biodiversity and Conservation (ICWEB) that will be held in Banjarbaru, South Kalimantan, Indonesia from November 12, 2019. This conference will be hosted by the Department of Biology, Faculty of Mathematics and Natural Sciences, Lambung Mangkurat University, Banjarbaru.

The theme of the conference is "Maintaining the tropical wetland biodiversity for better human welfare". This event will relate to an integrated global perspective for a map out the various drivers and alternative scenarios as an integrative solution for an update tropical wetland biodiversity and conservation issues. The conference will provide an ideal platform to share information and discuss their scientific results and experiences, with particular references to maintain tropical wetland initiatives.

Banjarbaru is a fast-growing city in the province of South Kalimantan, Indonesia, and famously known as an urban city with a unique natural landscape, a cultural diversity, and a friendly welcoming citizen. Moreover, Banjarbaru will become the center of a provincial government that its government is located in Banjarmasin today.

I can guarantee you that this conference will provide a full of intellectual experience as well as an unforgettable visit to Banjarbaru. We look forward to welcoming you to our place.

Yours sincerely,

Chairman,

Sasi Gendro Sari 